\title{
REORGANIZAÇÃO DOS SISTEMAS PÚBLICO E PRIVADO DA EDUCAÇÃO SUPERIOR NO BRASIL
}

\author{
REORGANIZATION OF THE PUBLIC AND PRIVATE \\ SYSTEMS OF HIGHER EDUCATION IN BRAZIL \\ LA RÉORGANISATION DES SYSTÈMES PUBLIC ET \\ PRIVÉ D’ENSEIGNEMENT SUPÉRIEUR AU BRÉSIL \\ REORGANIZACIÓN DE LOS SISTEMAS PÚBLICO Y \\ PRIVADO DE EDUCACIÓN SUPERIOR EN BRASIL
}

\author{
Luiz Fernandes Dourado*
}

\begin{abstract}
RESUMO
O presente artigo tem por objetivo analisar o processo de reorganização da educação superior no Brasil na década de 1990 por meio das alteraçôes efetivadas no campo jurídico e de seus desdobramentos nas politicas e gestão para esse nivel de ensino nos sistemas públicos e privados, que se configuraram em efetivo processo de reforma desse nivel de ensino, ainda que tenha prescindindo de participação efetiva dos diferentes segmentos da sociedade acadêmica, sob os auspicios da reforma do Estado e da centralidade conferida, nesse processo, ao setor privado. Aliado às análises efetivadas sobre o impacto da reorganização dos sistemas público e privado da educação superior, por meio de politicas de expansão, privatização e de alteração da identidade das IES, o presente artigo busca descortinar reflexōes e indicar principios basilares a serem efetivados em prol da construção de um processo de reestruturação da educação superior que tenha por norte o resgate da educação superior pública, democrática e de qualidade social entendida como um direito social inalienável.
\end{abstract}

Palavras-chave: Educação superior. Políticas e gestão. Sistemas. Expansão. Privatização. Mercantilização.

* Doutor em Educação pela Universidade Federal do Rio de Janeiro (UFRJ, 1997). Professor Titular de Políticas Educacionais da Faculdade de Educação e Programa de Pós-Graduação em Educação da Universidade Federal de Goiás. Pesquisador do CNPq (douradol@terra.com.br). 


\section{INTRODUÇÃO}

As análises sobre as políticas educacionais implementadas no Brasil para a educação superior, numa abordagem crítica, revelam um movimento de alterações significativas na lógica de organização e gestão induzidas pelo ideário neoliberal que presidiu a reforma do Estado no Brasil na década de 1990. Nessa ótica, intensificam-se, no campo da educação superior, políticas de diversificação e diferenciação institucional que priorizam dois desdobramentos articulados no campo: a naturalização das instituições não-universitárias e um processo de expansão do acesso à educação superior predominantemente privado. Ou seja, implementou-se um processo de reforma de feição pragmática, reduzindo, desse modo, o escopo de ação na educação superior à formação profissional, balizado pela racionalização do campo educativo por meio de lógica subjacente ao campo econômico stricto sensu.

Esse processo implicou alterações na concepção e organização da educação superior implementadas por mudanças na legislação educacional, ao mesmo tempo em que sinalizou para a diversificação e diferenciação institucional, secundarização do setor público, novos aportes de financiamento voltados para a educação superior privada, redução do escopo da autonomia universitária, entre outros. Tais alteraçôes implicaram, substantivamente, um processo de expansão matizado por precarização da qualidade da educação e por viés nitidamente privado, que resultou, ainda, em um complexo processo de reorganização dos sistemas público e privado da educação superior no Brasil.

\section{EXPANSÃO, PRIVATIZAÇÃO E NOVOS FORMATOS ORGANIZACIONAIS DA EDUCAÇÃO SUPERIOR}

A indissociabilidade ensino, pesquisa e extensão, após a aprovação da reforma universitária de 1968, colocava-se como norte político-pedagógico e jurídico para a organização e gestão da educação superior, preferencialmente, portanto, compreendendo as instituiçôes universitárias. Esse norte a ser consolidado, tendo em vista o grande número de instituiçôes de ensino superior isoladas existentes principalmente no setor privado, foi secundarizado pelas políticas de diversificação e diferenciação institucional implementadas no País a partir de 1995, balizadas, entre outras, pela adoção de organização acadêmica para a educação superior classificadas em universidades, centros universitários, faculdades integradas, faculdades, institutos superiores ou escolas superiores. ${ }^{1}$

Sguissardi (2000), ao analisar as políticas para a educação superior, destaca que esse processo de diferenciação institucional resultou no dualismo institucional desse nível de ensino fortemente marcado pela segmentação no campo por meio de instituições de ensino superior universitárias e não-universitárias, naturalizando, desse modo, no caso brasileiro, a hegemonia da educação superior centrada na formação profissional e reduzida às atividades de ensino, em detrimento das atividades de pesquisa.

Aliado a essas mudanças no que concerne à organização acadêmica da educação superior no Brasil, vivencia-se, na década de 1990, um claro processo expansionista, intensificado a partir de criação de novos cursos e instituições de natureza privada mercantil. 
Esse movimento de privatização na educação superior, articulado ao processo de reforma do Estado brasileiro, vai se efetivar, com forte apoio governamental, por meio da flexibilização das exigências para a abertura de cursos e instituições, pela composição privatista do Conselho Nacional de Educação e, paradoxalmente, por novas formas de financiamento ao setor privado (Fies, subsídios, bolsas universitárias, entre outros) e por uma paulatina secundarização das instituições de educação superior (IES) do setor público, especialmente as Instituiçôes Federais de Ensino Superior (Ifes).

Ao analisar o embate político-ideológico entre os defensores do ensino público e privado no Brasil, Dourado (2001 e 2001a) chama a atenção para os novos contornos assumidos pela promíscua relação entre as esferas pública e privada ${ }^{2}$ intensificada no Brasil, sobretudo, nos anos 90, na medida em que, em muitos casos, o poder público foi acionado para subvencionar direta ou indiretamente o setor privado. Desse modo, afirma que

o uso de prédios e equipamentos públicos tem sido uma constante, mediante contratos, comodatos, cessão ou outras soluções jurídicas, em detrimento do Poder Público. O apoio financeiro, em alguns casos, efetivado em várias localidades do país, por meio de doação de terrenos, edificação de prédios, compras de livros e equipamentos, pagamento de consultorias e projetos acadêmicos, entre outros. Os casos de subvençôes do Poder Público, sobretudo o municipal, têm se dado com o aval do Poder Legislativo, em muitos casos. Corrobora para a implementação dessas subvençôes a mística da implantação de Instituições de Ensino Superior, vista como fator de prestígio e, fundamentalmente, como eficaz marketing nos processos eleitorais (2001a, p. 291).

A criação e a implementação de fundações de educação superior, de natureza ambígua, oficializaram manobras as mais diversas do setor privado, objetivando a sua expansão à luz do setor público, por meio de subsídios diretos ou indiretos contratos de prestação de serviços, o que, entre outros benefícios, permitiu a criação de IES e cursos superiores com tramitação no âmbito dos Conselhos Estaduais de Educação.

Dourado (2001, p.182-183), ao analisar o processo expansionista da educação superior em Goiás, envolvendo o poder público municipal e o setor privado, por meio da criação de fundações educacionais, afirma que

De maneira geral, o processo fundacional no Estado tem se associado, prioritariamente, a interesses privatistas, já que os municípios têm sido apenas um canal que facilita a autorização e possibilita as subvenções, cabendo às entidades privadas (associaçôes de ensino) não só a exploração do ensino superior pago, mas também os benefícios diretos ou indiretos a elas asseguradas pelos municípios, tais como repasse de verbas, pagamentos de bolsas de estudo, etc. Cabem também aos municípios os esforços em favor da autorização e reconhecimento dos cursos e, posteriormente, por intermédio das pressões da comunidade, o empenho em favor da continuidade e regularização dos cursos.

[...] Essa engenharia jurídica facilitou, ainda, a criação de canais para burlar a legislação de ensino vigente. A dificuldade em fiscalizar essas empreitadas vem sendo denunciada e esbarra não só na carência de estrutura do Conselho Estadual, mas também na falta de decisão política 
para a imposição de uma norma eficaz. Em alguns casos, as alterações nas mantenedoras negligenciaram, inclusive, a tramitação legal básica via Conselho, permitindo atos arbitrários e ilegais, que foram posteriormente regularizados, a partir de práticas clientelísticas e privatistas desses órgãos, que em tese teriam o papel de coibir os abusos.

Outra análise que resgata processo similar, envolvendo o poder público estadual e as fundações, foi desenvolvida por Miranda ao buscar apreender os contornos ambíguos no processo de estruturação da Universidade do Estado de Minas Gerais. Essa universidade, criada pela Constituição do Estado que foi promulgada em 21 de setembro de 1989, previa em sua estruturação a absorção de fundações de ensino superior que foram instituídas pelo Estado ou contaram com a sua participação. Miranda (2005), ao analisar a perspectiva de criação dessa universidade, sob a ótica do processo legislativo, desde a sua criação em 1989 até 2004, vai descortinando um processo complexo de interpenetração entre as esferas pública e privada, cuja ambigüidade remete à participação do poder público estadual na criação das fundações e, posteriormente, na não-efetivação dessas instituições como condição para a efetiva implementação da UEMG. Nesse cenário, afirma que

A implementação da UEMG foi ofuscada pela situação das Fundações privadas. Pelo que se observou no processo legislativo, os Deputados atuaram mais disciplinando a situação dessas entidades do que exatamente na implementação da UEMG. As Fundaçôes privadas, que deveriam ser extintas, se fossem cumpridas as disposiçôes da CE-MG/89, acabaram se fortalecendo. Tanto as Fundações que optaram pela UEMG quanto as que preferiram se desvincular do Estado, se beneficiaram das ações do Legislativo, que as manteve vinculadas ao CEE-MG, descumprindo-se assim, flagrantemente, a legislação federal vigente.

Essas análises apontam para a complexidade do processo de privatização da educação superior no Brasil, ao assumir percursos obscuros que expressam a manutenção da natureza e égide patrimonial do Estado brasileiro.

A respeito do processo de privatização no campo educacional, Leher (2004, p. 92) alerta que "a privatização é um processo muito mais profundo do que os estudiosos e sindicalistas previam há duas décadas. Mais do que a cobrança de mensalidades tout court, invade todas as esferas da vida social, esculpindo um renovado território em que também a educação é fast food. Há confluência de interesses entre os grupos empresariais e suas entidades, o governo e os organismos internacionais".

Em consonância com as premissas defendidas pelos organismos multilaterais e pela agenda internacional para os países em desenvolvimento, o Brasil, na década de 1990, enfatizou como eixo central das políticas educacionais a universalização do ensino fundamental. Diante dessa deliberação política e objetivando desobrigar-se da educação superior, o governo federal, sobretudo na gestão Fernando Henrique Cardoso, assumiu postura ofensiva contra o ensino superior público, taxando-o de ineficiente, elitista e de altamente dispendioso aos cofres públicos. Nessa direção, tais deliberaçôes contrapõem a educação básica à educação superior, advogando, portanto, a centralidade política da ação do poder público no financiamento e expansão do ensino fundamental 
e, progressivamente, da educação infantil e do ensino médio, em detrimento da educação superior.

Tal perspectiva, assentada no falso dilema de que a garantia da educação básica implica o redirecionamento da educação superior, naturaliza a condição do Brasil como país periférico dependente e, ao mesmo tempo, cria as condiçóes objetivas para a expansão privada mercantil da educação superior em larga escala no País.

Corbucci (2004, p. 685), ao discutir o falso dilema - financiamento da educação básica em contraposição à educação superior - afirma que "o problema do financiamento da educação brasileira não reside no fato de o gasto com a educação superior ser excessivo, e sim que os investimentos na educação básica são insuficientes”. Destaca, ainda, que tal política resultaria no desmantelamento de um sistema que oferece educação de qualidade, advertindo para o fato de que "tal medida reduziria as chances de ingresso dos mais pobres".

A opção do governo federal, ao enfatizar como prioridade a expansão do ensino fundamental, foi de secundarização das Instituições Federais de Educação Superior (Ifes) e de adoção de medidas de flexibilização dos processos de criação de instituições de educação superior e de abertura de novos cursos e vagas, o que legitimou a política deliberada de expansão privada desse nível de ensino em ritmo acelerado. ${ }^{3}$

Nesse cenário, ocorre a intensificação do processo de privatização da educação superior, sobretudo a partir de 1995, referendado por vários dispositivos legais (decretos, portarias, resoluções, aprovação da Lei de Diretrizes e Bases da Educação Nacional e a aprovação do Plano Nacional de Educação). Nesse contexto, a lógica expansionista, com base em política de flexibilização, permitiu o incremento das matrículas e, conseqüentemente, a consolidação da hegemonia do setor privado, que ampliou o escopo de sua atuação, passando a responder, em 2002, por 83,34\% das 1.773 .087 vagas para a educação superior.

Tabela I - Evolução do número de vagas oferecidas em vestibular e outros processos seletivos

\begin{tabular}{|c|c|c|c|c|c|c|c|c|c|c|}
\hline \multirow{3}{*}{ Ano } & \multirow{2}{*}{\multicolumn{2}{|c|}{ Total }} & \multicolumn{8}{|c|}{ Categoria Administrativa } \\
\hline & & & \multicolumn{2}{|c|}{ Federal } & \multicolumn{2}{|c|}{ Estadual } & \multicolumn{2}{|c|}{ Municipal } & \multicolumn{2}{|c|}{ Privada } \\
\hline & Vagas & $\begin{array}{l}\text { Ano- } \\
\text { Base } \\
1980\end{array}$ & Vagas & $\begin{array}{l}\text { Ano- } \\
\text { Base } \\
1980\end{array}$ & Vagas & $\begin{array}{l}\text { Ano- } \\
\text { Base } \\
1980\end{array}$ & Vagas & $\begin{array}{l}\text { Ano- } \\
\text { Base } \\
1980\end{array}$ & Vagas & $\begin{array}{l}\text { Ano- } \\
\text { Base } \\
1980\end{array}$ \\
\hline 1980 & 404.814 & 100 & 65.406 & 100 & 33.618 & 100 & 27.916 & 100 & 277.874 & 100 \\
\hline 1985 & 430.482 & 106 & 67.307 & 103 & 41.055 & 122 & 32.912 & 118 & 289.208 & 104 \\
\hline 1990 & 502.784 & 124 & 70.881 & 108 & 55.232 & 164 & 28.896 & 104 & 347.775 & 125 \\
\hline 1995 & 610.355 & 151 & 84.814 & 130 & 61.352 & 182 & 31.979 & 115 & 432.210 & 156 \\
\hline 2000 & 1.216 .287 & 300 & 120.486 & 184 & 96.179 & 286 & 28.967 & 104 & 970.655 & 349 \\
\hline 2002 & 1.773 .087 & 438 & 124.196 & 190 & 132.270 & 393 & 38.888 & 139 & 1.447 .733 & 532 \\
\hline
\end{tabular}

no ensino superior de graduação presencial, por categoria administrativa - Brasil 1980/2002 
Fonte: MEC/Inep/2004 - Mapa da educação superior no Brasil.

A evolução do número vagas oferecidas em vestibular e em outros processos seletivos sinaliza, desse modo, para a ampliação substantiva da educação superior privada, sobretudo na segunda metade da década de 1990 . No setor privado, houve, no período, o incremento de matrículas em universidades, passando de 660.000 em 1997 para 1.235 .000 em 2002 (por meio de expansão da ação institucional, criação de novas universidades, cursos e vagas), a explosiva criação de centros universitários, instituições tipicamente de ensino, que saltaram de 30.000 matrículas em 1997 para 416.000 em 2002, e o incremento de matrículas em faculdades integradas e demais estabelecimentos isolados, que passaram de 496.000 matrículas em 1997 para 778.000 matrículas em 2002. O setor público, no período, manteve uma tendência oposta ao setor privado, na medida em que consolidou suas ações de maneira predominante em universidades, ampliando, nessa dependência administrativa, o número de matrículas de $666.000 \mathrm{em}$ 1997 para 916.000 em 2002. As demais dependências responderam por apenas 97.000 matrículas em 1997 e 136.000 em 2002.

Nesse cenário, é oportuno situar que as Ifes no Brasil, a despeito da retração paulatina de recursos ${ }^{4}$ e do seu quadro docente e técnico-administrativo nos últimos anos, vivenciaram uma expansão de sua atuação no ensino e na extensão. Tal expansão efetivou-se à custa de lutas pela sobrevivência institucional em um cenário sombrio de precarização das condiçôes de trabalho e de infra-estrutura que, em alguns casos, reduziu o escopo das açōes de gestão e organização acadêmica das Ifes, merecendo destaque a secundarização, em muitas instituições, das atividades de pesquisa.

Tal dinâmica expansionista vai consubstanciar nas Ifes um processo de alteração significativa da identidade dessas instituições, por meio da adoção de açôes, programas e políticas direcionadas à garantia da sobrevivência institucional, que, em muitos casos, tem se caracterizado pela secundarização das atividades de pesquisa e/ou pelo direcionamento dessas atividades às necessidades do mercado; pela criação e naturalização das fundações de apoio de caráter privado como espaço de flexibilização da gestão acadêmica e financeira e de obtenção de fontes alternativas de financiamento da instituição e pela intensificação no cotidiano das Ifes de um padrão acadêmico pautado pela lógica pro-

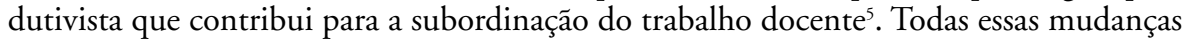
vão conferindo à educação superior pública federal um processo de metamorfose ${ }^{6}$ que as direciona à política de ajuste à lógica e aos princípios de mercado, provocando um distanciamento das finalidades institucionais e históricas destas no que concerne à garantia de educação pública e de qualidade. 


\begin{tabular}{|l|c|c|c|c|c|c|c|c|c|}
\hline \multirow{2}{*}{$\begin{array}{l}\text { Organização } \\
\text { Acadêmica }\end{array}$} & \multicolumn{3}{|c|}{ Total } & \multicolumn{3}{c|}{ Pública } & \multicolumn{3}{c|}{ Privada } \\
\cline { 2 - 11 } & 1994 & 1997 & 2002 & 1994 & 1997 & 2002 & 1994 & 1997 & 2002 \\
\hline Total & $\mathbf{1 . 6 6 1}$ & $\mathbf{1 . 9 4 6}$ & $\mathbf{3 . 4 8 0}$ & $\mathbf{6 9 0}$ & $\mathbf{7 5 9}$ & $\mathbf{1 . 0 5 2}$ & $\mathbf{9 7 1}$ & $\mathbf{1 . 1 8 6}$ & $\mathbf{2 . 4 2 8}$ \\
\hline Universidade & 1.035 & 1.326 & 2.151 & 572 & 666 & 916 & 463 & 660 & 1.235 \\
\hline $\begin{array}{l}\text { Centros } \\
\text { Universitários }\end{array}$ & $\ldots$ & 30 & 430 & $\ldots$ & - & 15 & $\ldots$ & 30 & 416 \\
\hline $\begin{array}{l}\text { Faculdades } \\
\text { Integradas }\end{array}$ & 203 & 162 & 180 & 10 & 1 & 7 & 193 & 161 & 173 \\
\hline $\begin{array}{l}\text { Faculdades, } \\
\text { Escolas e } \\
\text { Institutos }\end{array}$ & 423 & 426 & 676 & 108 & 92 & 77 & 314 & 335 & 599 \\
\hline $\begin{array}{l}\text { Centros de } \\
\text { Educação } \\
\text { Tecnológica }\end{array}$ & $\ldots$ & $\ldots$ & 43 & $\ldots$ & $\ldots$ & 37 & $\ldots$ & $\ldots$ & 6 \\
\hline
\end{tabular}

Tabela 2 - Evolução da matrícula no ensino superior de graduação presencial,

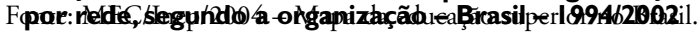

A distribuição percentual do número de instituições de ensino superior por tamanho revela a intensificação, em 2002, do predomínio de instituições pequenas, com até 1.000 alunos (68,7\%), ainda que essas IES sejam responsáveis por apenas $10,6 \%$ das matrículas. Tal processo indica a pulverização das instituições educacionais e, paradoxalmente, a concentração de parte dessas instituições nas mãos de grandes empresários do setor. Essa dinâmica desigual e combinada expressa as novas bases de (re)organização do sistema de educação superior no País. Merece destaque, ainda, a naturalização de formatos educacionais híbridos, objeto de parcerias e convênios entre instituições nacionais e internacionais, que propiciam ao campo novos protagonistas e complexas dinâmicas acadêmica e de padrão organizativo.

\begin{tabular}{|l|c|c|c|c|}
\hline \multirow{2}{*}{$\begin{array}{c}\text { Tamanho de instituição } \\
\text { (número de alunos) }\end{array}$} & \multicolumn{2}{c|}{ Matrícula } & \multicolumn{2}{c|}{$\mathbf{N}^{\circ}$ de instituições } \\
\cline { 2 - 5 } & $\mathbf{1 9 9 4}$ & $\mathbf{2 0 0 2}$ & $\mathbf{1 9 9 4}$ & $\mathbf{2 0 0 2}$ \\
\hline Total & $\mathbf{1 0 0 , 0 0}$ & $\mathbf{1 0 0 , 0 0}$ & $\mathbf{1 0 0 , 0 0}$ & $\mathbf{1 0 0 , 0 0}$ \\
\hline Até 1000 & 1.035 & 1.326 & 2.151 & 572 \\
\hline Mais de 1000 até 2000 & $\ldots$ & 30 & 430 & $\ldots$ \\
\hline Mais de 2000 até 5000 & 203 & 162 & 180 & 10 \\
\hline Mais de 5000 & 423 & 426 & 676 & 108 \\
\hline
\end{tabular}

Tabela 3 - Distribuição percentual da matrícula no ensino superior de graduação presencial e do 
número de instituições por tamanho da instituição (número de alunos) - Brasil - 1994 e 2002

Fonte: MEC/Inep/2004 - Mapa da educação superior no Brasil.

A intensificação do processo de expansão da educação superior no Brasil é resultado, portanto, dos marcos organizacionais e, sobretudo, das políticas de gestão assumidas pelo governo central, cuja lógica resultou na paulatina concentração de instituiçóes e matrículas na educação superior privada e, paradoxalmente, nos limites desse processo expansionista que impulsiona, cada vez mais, o poder público para o financiamento direto e/ou indireto dessas IES privadas.

Depreende-se, desse quadro, que tais políticas possibilitaram, de fato, a implementação de um processo de efetiva e orgânica reforma da educação superior, que alterou a lógica organizativa dos sistemas público e privado e, conseqüentemente, o campo desse nível de ensino no País. Esse processo, em que pese o discurso oficial, não se pautou pela garantia de um padrão de qualidade para a educação superior, na medida em que a abertura indiscriminada de cursos e instituições, nos diversos municípios brasileiros, não se fez acompanhar de mecanismos de gestão e avaliação ${ }^{7}$ que assegurassem um patamar básico de qualidade social. Na contramão dessa lógica, o que se verificou, como tendência hegemônica do processo expansionista, foram políticas de aligeiramento dos processos formativos e a redução da educação superior às atividades de ensino, por meio da naturalização dos processos de mercantilização e de financiamento público do setor privado.

\section{AS MUDANÇAS NA EDUCAÇÃO SUPERIOR E A REORGANIZAÇÃO DOS SISTEMAS PÚBLICOS E PRIVADOS NO BRASIL}

O debate internacional sobre educação superior, com dinâmicas e processos diferenciados em sintonia com os processos sociais mais amplos, resultaram em ações, programas e políticas voltados para a necessária expansão desse nível de ensino, tendo em vista a efetiva ampliação da demanda motivada, entre outros, pelas mudanças no mundo do trabalho e da produção e pela melhoria dos indicadores educacionais. Todavia, tal processo tem implicado em impactos profundos na visão humanista e no papel social destinado à educação superior. O cenário atual caracteriza-se por um contexto em que o pragmatismo neoliberal tem sido o paradigma do redirecionamento desse nível de ensino pautado, hegemonicamente, pela secundarização da liberdade acadêmica e pela subordinação a um processo de mercadorização marcado pela ênfase na formação profissional e na competitividade, o que vem afetando, sobremaneira, a identidade institucional, os processos formativos, a avaliação e o financiamento público da educação superior.

Como analisamos anteriormente, na década de 1990, particularmente no governo FHC, adotou-se uma política deliberada de expansão da educação superior por meio da flexibilização dos processos e pela adoção de um modo pautado pela diversificação, e a diferenciação do sistema de educação superior, de modo a acomodar as demandas expansionistas de um novo ensino superior privado de feição nitidamente mercantil. Essas políticas contribuíram, sobremaneira, para o redirecionamento dos sistemas públicos e privados da educação superior no País. Esse processo de reorganização dos sistemas, privatização e dos marcos organizativos tem sido abordado por vários estudos ${ }^{8}$ na área, 
indicando a relevância desse processo para a compreensão da complexificação do cenário das políticas e gestão para a educação superior no País.

Essas mudanças no campo refletiram-se na função social da educação superior: ao romper com o princípio histórico da defesa da indissociabilidade entre ensino, pesquisa e extensão; ao alterar a identidade das universidades já constituídas e consolidar a instituição de novas universidades mercantis; e, por meio de ajuste mercadológico, ao permitir a criação de centros universitários que, a despeito de gozar de algumas prerrogativas das universidades (autonomia para criar, organizar e extinguir cursos e programas, dentre outros), se caracterizam como instituições tipicamente de ensino.

Cunha (2004, p. 807), ao analisar o papel dos centros universitários no âmbito das políticas de organização acadêmica implementadas no País por meio dos Decretos de $\mathrm{n}$. 2.306/97 e 3.860/01, realça o papel político conferido a esse novo formato organizacional no processo de reforma da educação superior, afirmando que, "assim, os centros universitários ocuparam o lugar, no discurso reformista oficial, da universidade de ensino, definida por oposição à universidade de pesquisa, a que seria a universidade plenamente constituída".

Altera-se, desse modo, a lógica de constituição do campo universitário e se efetiva a apreensão de uma lógica pragmática e mercantil que contribui efetivamente para a implementação de mudanças na natureza, no papel social e nas finalidades das universidades, inclusive das públicas, e, conseqüentemente, resulta na reorganização dos sistemas público e privado de educação superior.

Esse processo implicou mudanças na concepção e organização da educação superior implementadas por alterações na legislação educacional, ao mesmo tempo em que sinalizou para a diversificação institucional, secundarização do setor público, diversificação de fontes de financiamento voltadas para a educação superior privada, redução do escopo da autonomia universitária. Tais alteraçóes implicaram, substantivamente, um processo de expansão caracterizado pela precarização da qualidade da educação e por viés nitidamente privado, reforçado, sobremaneira, pela interpenetração entre as esferas pública e privada, em detrimento da educação superior pública.

Compreender esse processo, visando à retomada de políticas educacionais que tenham por norte a reestruturação da educação superior, implica problematizar a organicidade estabelecida, sob a lógica pragmática, entre os vários instrumentos e mecanismos de reforma da educação superior e o processo de reforma de Estado, em curso no Brasil, cujo balizamento efetivou-se por um processo de minimização do papel do Estado no tocante às políticas públicas. Nesse sentido, a discussão sobre o papel social e a identidade das instituiçôes de ensino superior, especialmente as universidades, implica articular concepções que considerem: a indissociabilidade ensino, pesquisa e extensão; ${ }^{9}$ políticas de financiamento do setor público; autonomia universitária; e políticas de avaliação formativa que contribuam efetivamente com o desenvolvimento institucional das instituiçóes. 


\section{A REORGANIZAÇÃO DOS SISTEMAS PÚBLICO E PRIVADO DE EDUCAÇÃO SUPERIOR: A DEFESA DE UM NOVO ETHOS POLÍTICO-ACADÊMICO E SOCIAL}

A reorganização dos sistemas público e privado de educação superior por meio da defesa de um novo ethos político-acadêmico e social, que se direcione para o fortalecimento, a democratização e a melhoria da qualidade nesse nível de ensino, constitui um amplo desafio, que transcende o escopo de atuação do Ministério da Educação, mas que tem nesse ministério locus privilegiado. Esse projeto deverá se articular a efetivas mudanças na égide patrimonial e clientelista do Estado brasileiro, entendido em uma visão ampliada como resultado da articulação entre sociedade civil e política, em consonância ao estabelecimento de processos de gestão e de regulação que direcionem o fundo público para a expansão e democratização da educação superior pública e gratuita no País, sem negligenciar, contudo, a necessidade do estabelecimento de novos marcos de regulação e gestão que contribuam para a melhoria da qualidade e para um processo de progressiva desmercantilização da educação superior privada.

Nessa ótica, propostas de revitalização do sistema público de educação superior, assumindo centralidade no processo de reforma e, portanto, de reorganização dos sistemas público e privado, implicam ajustes estruturais na proposição de políticas, na lógica de organização, gestão e no padrão de financiamento da educação superior. Neste sentido, a idéia de reforma desse nível de ensino não deve limitar-se a ações emergenciais, pautadas pela manutenção estrutural das políticas vigentes.

Aliado à defesa da centralidade da educação superior pública, é fundamental garantir o estabelecimento de novas bases para o financiamento desse nível de ensino, bem como a implementação de políticas específicas visando o fortalecimento do setor público, articuladas a mudanças estruturais que possam contribuir para a expansão da educação superior com qualidade social.

Outro princípio fundamental refere-se à garantia de mecanismos que possibilitem a efetivação do caráter auto-aplicável da autonomia por força de dispositivo constitucional, bem como de um melhor delineamento da concepção de autonomia e das possibilidades de sua efetivação pelas universidades públicas e privadas, rompendo com a dimensão economicista que historicamente tem buscado reduzir a autonomia das instituiçôes, a captação e a administração flexível de recursos.

A estruturação de um Sistema Nacional de Avaliação, articulando a educação básica e a superior, é vital para a implementação dos novos marcos regulatórios para os sistemas público e privado de educação superior no País.

A derrubada dos vetos ao Plano Nacional de Educação (PNE) e a revisão de objetivos e metas adequando-os à melhoria dos processos formativos e aos novos marcos regulatórios, bem como a ampliação progressiva dos percentuais do Produto Interno Bruto destinados à educação pública, nos diferentes níveis e modalidades, constituem um importante movimento na construção de um novo padrão de qualidade e de democratização da educação pública. 
Nesse sentido, a participação ativa e efetiva da sociedade se faz necessária, objetivando construir um outro patamar para a reorganização dos sistemas público e privado no Brasil, sobretudo no cenário em que se deslinda uma proposta governamental para a reestruturação da educação superior, que considere questôes como:

1) Concepção ampla de educação superior - pautada pela indissociabilidade ensino, pesquisa e extensão, padrão unitário de qualidade, gestão democrática, avaliação institucional - em detrimento do aligeiramento dos processos formativos e da redução da educação superior às atividades de ensino por meio da reeestruturação das políticas de regulação e gestão de reforma da educação superior;

2) Estabelecimento de política de acompanhamento e regulação das políticas para a educação superior: abertura de cursos e instituiçôes acompanhada de mecanismos de gestão e avaliação que assegurem um patamar básico de qualidade social;

3) Estabelecimento de ações e políticas visando à expansão com qualidade social da educação superior por meio do resgate e da consolidação do papel das instituiçõos públicas, sobretudo no que tange à resolução de problemas sociais, formação de recursos humanos e geração de conhecimento, de modo a contribuir efetivamente para a implementação de um projeto de desenvolvimento do País marcado pela inclusão social;

4) Ampliação do acesso, por meio de políticas e ações afirmativas, visando à inclusão de grupos sociais historicamente excluídos ou secundarizados na atual dinâmica das IES (cotas, cursos noturnos, outras modalidades de democratização do acesso e permanência);

5) Reestruturação administrativa, pedagógica e financeira das IES e consolidação de um projeto de autonomia universitária conforme preconiza a Constituição Federal;

6) Revisão do papel das fundações de apoio e definição de políticas nacionais de incentivo à pesquisa, desenvolvimento científico e tecnológico, resguardando a identidade das IES;

7) Consolidação institucional das IES, por meio de uma sólida política de formação e investigação que contribua para o enfrentamento de questôes sociais e, concomitantemente, com o desenvolvimento tecnológico e avanço do conhecimento no País.

Estes são desafios a serem enfrentados coletivamente em prol do redirecionamento dos sistemas público e privado de educação superior, tendo por norte político a centralidade do resgate da educação superior pública, democrática e de qualidade social entendida como um direito social inalienável.

\section{CONSIDERAÇÕES FINAIS}

A definição de prioridades do Estado brasileiro para a educação superior democrática e de qualidade social se coloca, portanto, como um desafio a ser construído coletivamente, envolvendo a sociedade civil e política, e, nesse processo, deve se articular a processos macro-estruturais que priorizem as políticas públicas e que caminhem para a democrati- 
zação e a universalização dos direitos sociais daí decorrentes, destacando-se a garantia de educação básica e superior pública e gratuita. Assim, a participação ampla deverá ser um balizador da nova universidade - especialmente a pública - que se quer construir: uma universidade autônoma comprometida com a efetiva inclusão social, espaço de fortalecimento do ideário democrático e da disseminação e produção do conhecimento.

Nesse cenário, compete ao poder público a garantia de recursos e condiçôes para a implementação da autonomia e a consolidação do sistema público de educação superior. Às instituições públicas compete, nesse processo, a busca contínua de melhoria de seus processos formativos e a implementação de políticas visando à democratização dessas IES a toda a sociedade brasileira, sem prescindir, contudo, do seu papel estratégico, articulado às políticas de desenvolvimento do País, por meio da produção e disseminação de conhecimento.

\section{Notas}

1. O art. 45 da LDB define que "A educação superior será ministrada em instituiçōes de ensino superior, públicas ou privadas, com variados graus de abrangência ou especialização" (BRASIL, 1996). O artigo 70 do Decreto 3.860/2001 define que: "quanto à sua organização acadêmica, as instituições de ensino superior do Sistema Federal de Ensino classificam-se em: I - universidades; II - centros universitários; e III faculdades integradas, faculdades, institutos superiores ou escolas superiores".

2. A respeito da relação público e privado ver Adrião e Peroni (2005).

3. A respeito das políticas de acesso à educação superior ver PEIXOTO (2004) e PINTO (2004).

4. A esse respeito, conferir Amaral (2003), que desenvolve estudo substantivo sobre o financiamento das Ifes, indicando uma lógica sempre decrescente dos recursos alocados pelo Governo Federal às Ifes no período de 1998-2001.

5. A esse respeito, é importante destacar, entre outras, a instituição da Gratificação de Estímulo a Docência para o magistério superior das Instituiçôes Federais de Ensino Superior (Ifes) como mecanismos de estímulo à produtividade docente, que, segundo Catani e Oliveira (1999, p. 66), estimulou "mudanças no comportamento docente e na natureza do trabalho acadêmico". Mancebo e Franco (2004), ao analisarem as mudanças no trabalho docente em articulação ao processo de globalização, ressaltam, entre outras consequiências desse processo, o aumento das tensões no ambiente de trabalho e a flexibilização de processos e de produtos.

6. Catani e Oliveira (2002, p. 57), ao abordarem a lógica constitutiva de reorganização da educação superior no Brasil, e especialmente do processo de ajustamento das universidades públicas federais a esse cenário, destacam o quadro de metamorfose vivenciado por essas instituiçôes, que tornam-se "...mais dependentes das determinações políticas e das metas do executivo, além de mais mercantilizadas na forma de produção acadêmica."

7. A respeito dos mecanismos de gestão e de avaliação da educação superior no País, vários teóricos, dentre eles Coelho (2003), Dias Sobrinho (2003), Dias Sobrinho; Ristoff (2002), Gomes (2002) Ristoff (2003), Catani; Dourado; Oliveira (2002), analisam os limites interpostos a um processo estandardizado de avaliação da educação superior, implementado no Brasil na segunda metade da década de 90 , que implicou na alteração de objetivos, valores e processos educativos, ao promover mudanças significativas na gestão universitária, no trabalho acadêmico e nos processos de formação profissional.

8. Dentre os estudos é oportuno destacar Cunha (1997), Dourado (2002), Catani; Oliveira (2002), Neves (2002), Sguissardi (2000), Silva Júnior (2002), Sguissardi; Silva Júnior (2001).

9. A respeito do papel da universidade como espaço de produção de conhecimento e pensamento crítico, ver Fávero, 2003.

10. Este artigo não se propôs a analisar as ações, programas e políticas implementadas pelo Governo Lula a partir de 2003, na medida em que as análises aqui apresentadas, sem negligenciar esse processo e os contornos assumidos, destacando políticas privatistas para o setor (tais como Lei de Inovação Tecnológica, 
Parcerias Públicas e Privadas e o Programa Universidade para Todos - Prouni), tiveram por centralidade o desvelamento das políticas cristalizadas nos processos de organização e de gestão na educação superior adotadas pelo governo passado, e que ainda estão em vigor, a partir de uma perspectiva analítica de alteração estrutural das mesmas em contraposição a lógica privatista e mercantil que as delinearam. A respeito do processo de reforma em curso no País, ver, dentre outros, Chaves (2005), Leher (2004), Mancebo (2004), Trindade (2004) e Sguissardi (2005), bem como documentos oficiais como: grupo de trabalho interministerial, bases para o enfrentamento de crise emergencial das universidades federais e roteiro para a reforma universitária brasileira (2003), Projeto de Lei n. 3.627/2004 que institui o Prouni, Reforma da Educação Superior, reafirmando princípios e consolidando diretrizes da reforma da educação superior. Documento II, 2004.

\section{Referências}

ADRIÃO, Theresa; PERONI, Vera (Orgs.). O público e o privado na educação: interfaces entre Estado e sociedade. São Paulo: Xamã, 2005.

AMARAL, Nelson Cardoso. Financiamento da educação superior: Estado versus mercado. São Paulo: Cortez e Edunimep, 2003.

BRASIL. Grupo de Trabalho Interministerial. Bases para o enfrentamento da crise emergencial das universidades federais e roteiro para a Reforma Universitária Brasileira. Brasília: 15 de dezembro de 2003.

. Ministério da Educação e do Desporto. Plano Nacional de Educação. Brasília: MEC/Instituto Nacional de Estudos e Pesquisas Educacionais Anísio Teixeira, 2001.

. Lei de Diretrizes e Bases da Educação Nacional. Lei n. 9.394, de 20 de dezembro de 1996. Diário Oficial da União, Brasília, 23 dez. 1996, p. 27.894.

. Ministério da Educação. Reforma da educação superior: reafirmando princípios e consolidando diretrizes da reforma da educação superior. Documento II. Brasília: MEC, 2004.

. Casa Civil. Exposição de motivos n. 355/2003; PL n. 2.546/2003. Dispóem sobre a parceria públicoprivado. Brasília: 2003.

. Projeto de Lei n. 3582/2004. Dispóe sobre a instituição do Programa Universidade para Todos - Prouni, regula a atuação de entidades beneficentes de assistência social no ensino superior e dá outras providências. Brasília: 2004. . Lei 10.973 (Lei de Inovação Tecnológica), de 02 de dezembro de 2004, que dispõe sobre incentivos à inovaçäo e à pesquisa científica e tecnológica no ambiente produtivo. Brasília: 2004.

CATANI, Afrânio Mendes; OLIVEIRA, João Ferreira. A gratificação de estímulo à docência (GED): alteraçôes no trabalho acadêmico e no padrão de gestão das Instituiçōes Federais de Ensino Superior (Ifes). In: DOURADO, Luiz Fernandes; CATANI, Afrânio Mendes (Orgs.). Universidade pública: políticas e identidade institucional. Campinas: Autores Associados; Goiânia: Edufg, 1999, p. 65-74.

Educação Superior no Brasil. Estruturação e metamorfose das universidades públicas. Petrópolis: Vozes, 2002. CHAVES, Vera Lúcia Jacob. Anteprojeto de lei da educação superior: quadro de análise. Belém: Graphitte, 2005 (Caderno ADUFPA).

COELHO, Ildeu Moreira. Educação superior: por uma outra avaliação. In: DOURADO, Luiz Fernandes; CATANI, Afrânio Mendes; OLIVEIRA, João Ferreira (Orgs.). Políticas e gestão da educação superior: transformações recentes e debates atuais. São Paulo: Xamã; Goiânia: Alternativa, 2003, p. 117-135.

CORBUCCI, Paulo Roberto. Financiamento e democratização do acesso à educação superior no Brasil: da deserção do Estado ao projeto de reforma. Dossiê Universidade: reforma e/ou rendição ao mercado? Educação e Sociedade, Campinas: Cedes, v. 25, n. 88, especial, p. 677-701, out. 2004. ISSN 0101-7330.

CUNHA, Luiz Antônio. Desenvolvimento desigual e combinado no ensino superior: Estado e mercado. In: Dossiê Universidade: reforma e/ou rendição ao mercado? Educação e Sociedade, Campinas: Cedes, v. 25, n. 88, especial, p. 795-817, out. 2004. ISSN 0101-7330.

. Nova reforma do ensino superior: a lógica reconstruída. Cadernos de Pesquisa, São Paulo: Fundação Carlos Chagas, n. 101, p. 20-49, 1997.

DIAS SOBRINHO, José. Avaliação ética e política em função da educação como direito público ou como mercadoria. Dossiê Universidade: reforma e/ou rendição ao mercado? Educação e Sociedade, Campinas: Cedes, v. 25, n. 88, especial, p. 703-725, out. 2004. ISSN 0101-7330. 
. Educação superior: flexibilização e regulação ou avaliação e sentido público. In: DOURADO, Luiz Fernandes; CATANI, Afrânio Mendes; OLIVEIRA, João Ferreira (Orgs.). Políticas e gestão da educação superior: transformações recentes e debates atuais. São Paulo: Xamã; Goiânia: Alternativa, 2003.

DIAS SOBRINHO, José; RISTOFF, Dilvo (Orgs.). Avaliação democrática: para uma universidade cidadã. Florianópolis: Insular, 2002.

DOURADO, Luiz Fernandes. A interiorização do ensino superior e a privatização do público. Goiânia: Edufg, 2001. . Reforma do Estado e políticas para a educação superior no Brasil nos anos 90. Educação e Sociedade, Campinas: Cedes, v. 23, n. 80, p. 235-253, set. 2002. ISSN 0101-7330.

O público e o privado na agenda educacional brasileira. In: AGUIAR, Márcia Ângela da Silva; FERREIRA, Naura Syria Carapeto (Orgs.). Gestão da educação: impasses, perspectivase compromissos. São Paulo: Cortez, 2001a.

DOURADO, Luiz Fernandes; CATANI, Afrânio Mendes; OLIVEIRA, João Ferreira (Orgs.). Políticas e gestão da educação superior. Transformaçôes recentes e debates atuais. São Paulo: Xamã; Goiânia: Alternativa, 2003.

Políticas públicas e reforma da educação superior no Brasil: impasses e perspectivas. Pró-posições, Campinas, v. 15, n. 3 (45), p. 91-115, set./dez. 2004.

. A política de avaliação da educação superior no Brasil em questão. In: DIAS SOBRINHO, José; RISTOFF, Dilvo (Orgs.). Avaliação democrática: para uma universidade cidadā. Florianópolis: Insular, 2002, p. 99-118.

FÁVERO, Maria de Lourdes de A. Universidade, espaço de produção do conhecimento e do pensamento crítico. In: DOURADO, Luiz Fernandes; CATANI, Afrânio Mendes; OLIVEIRA, João Ferreira (Orgs.). Politicas e gestão da educação superior. Transformações recentes e debates atuais. São Paulo: Xamã; Goiânia: Alternativa, 2003, p. 179-189.

GOMES, Alfredo Macedo. Política de avaliação da educação superior: controle e massificação. Educação e Sociedade, Campinas: Cedes, v. 23, n. 80, p. 277-300, set. 2002. ISSN 0101-7330.

LEHER, Roberto. Para silenciar os campi. Dossiê Universidade: reforma e/ou rendição ao mercado? Educação e Sociedade, Campinas: Cedes, v. 25, n. 88, p. 867-891, out. 2004. ISSN 0101-7330.

Expansão privada do ensino superior e heteronomia cultural: um difícil início de século. In: DOURADO, Luiz Fernandes; CATANI, Afrânio Mendes; OLIVEIRA, João Ferreira (Orgs.). Políticas e gestão da educação superior. Transformações recentes e debates atuais. São Paulo: Xamã; Goiânia: Alternativa, 2003.

MANCEBO, Deise. Reforma Universitária: reflexōes sobre a privatização e a mercantilização do conhecimento. Dossiê Universidade: reforma e/ou rendição ao mercado? Educação e Sociedade, Campinas: Cedes, v. 25, n. 88, p. 845-866, out. 2004. ISSN 0101-7330.

.; FRANCO, Maria Estela Dal Pai. Trabalho docente: uma análise das práticas intelectuais em tempos de globalização. In: DOURADO, Luiz Fernandes; CATANI, Afrânio Mendes; OLIVEIRA, João Ferreira (Orgs.). Políticas e gestão da educação superior. Transformações recentes e debates atuais. São Paulo: Xamã; Goiânia: Alternativa, 2003, p. 191-204.

MIRANDA, Alexandre B. A Universidade no papel: A implementação da universidade do Estado de Minas Gerais na perspectiva do processo legislativo (1989-2004). São Paulo: USP. Tese de Doutorado em Educação, 2005. Mimeografado.

NEVES, Lúcia Maria W. (Org.). O empresariamento da educação: novos contornos do ensino superior no Brasil dos anos 1990. São Paulo: Xamã, 2002.

PEIXOTO, Maria do Carmo L. (Org.). Universidade e democracia. Experiências e alternativas para a ampliação do acesso à universidade pública brasileira. Belo Horizonte: Edufmg, 2004.

PINTO, José Marcelino de Rezende. O acesso à educação superior no Brasil. Dossiê Universidade: reforma e/ou rendição ao mercado? Educação e Sociedade, Campinas: Cedes, v. 25, n. 88, especial, p. 727-756, out. 2004. ISSN 0101-7330.

RISTOFF, D. I. Avaliação da Educação Superior: flexibilização e regulação. In: DOURADO, Luiz Fernandes; CATANI, Afrânio Mendes; OLIVEIRA, João Ferreira (Orgs.). Políticas e gestão da educação superior. Transformações recentes e debates atuais. São Paulo: Xamã; Goiânia: Alternativa, 2003, p. 137-157.

SGUISSARDI, Valdemar (Org.). Educação superior: velhos e novos desafios. São Paulo: Xamã, 2000.

. A universidade brasileira em tempos de Lula. Piracicaba, SP, 2005. Mimeografado.

.; SILVA JÚNIOR, João dos Reis. Novas faces da educação superior no Brasil: reforma do Estado e mudanças na produção. São Paulo: Cortez; Edusf, 2001.

SILVA JÚNIOR, João dos Reis. Reforma do Estado e da educação no Brasil de FHC. São Paulo: Xamã, 2002. 
TRINDADE, Hélgio. A República em tempos de Reforma Universitária: o desafio do Governo Lula. Dossiê Universidade: reforma e/ou rendição ao mercado? Educação e Sociedade, Campinas: Cedes, v. 25, n. 88, especial, p. 819- 844, out. 2004. ISSN 0101-7330.

\section{Reorganization of the public and private systems of higher education in Brazil}

Abstract

This article aims at analyzing the process of reorganization of higher education in Brazil during the decade of the 1990's by means of modifications in the juridical field and its follow-ups in the policies and management for this level of education in the public and private systems. These are configurated in an effective reform process of this level of education even if it was done without the effective participation of the different segments of the academic community and under the cover of the State reform and the centrality conferred to the private sector in this process. In conjunction with the analyses made of the impact on the reorganization of the private and public higher education systems and by means of policies of expansion, privatization and altering of the identity of higher education institutions, this study tries to uncurtain the reflections and indicate the basic principles to be used in favor of the construction of a restructuring process for higher education which saveguards public, democratic and social quality higher education understood as an unquestionable social right.

Keywords: Higher education. Policies and management. Systems. Expansion. Privatization. Merchandising.

\section{La réorganisation des systèmes public et privé d'enseignement supérieur au Brésil Résumé}

L'article a comme objectif analyser le processus de réorganisation de l'enseignement supérieur au Brésil au cours des années 1990 par des modifications effectuées dans le champs juridique et ses repercussions sur les politiques et gestion pour ce niveau d'enseignement dans les systèmes public et privé. Ces changements se sont configurés dans un processus effectif de réforme de ce niveau d'enseignement même sills ont éte fait sans la participation réelle des différents segments de la communauté académique, mais sous les auspices de la réforme de l'État et de la centralité conférée au secteur privé au long de ce processus. Allié aux analyses effectuées sur l'impacte de la réorganisation des systèmes public et privé d'enseignement supérieur par des politiques d'expansion, de privatisation et de changement de l'identité des institutions d'enseignement supérieur, cet article cherche à dévoiler les réflections et indiquer les principes de base que doivent être mis en place en faveur de la construction d'un processus de réstructuration de l'enseignement supérieur qui a pour direction la sauvegarde de l'enseignement supérieur public, démocratique et socialement de qualité comme um droit social inaliénable.

Mots clefs : Enseignement supérieur. Politiques et gestion. Systèmes. Expansion. Privatisation. Mercantilisation.

\section{Reorganización de los sistemas público y privado de educación superior en Brasil} Resumen

El presente artículo tiene como objetivo analisar el proceso de organización de la educación superior en Brasil en la década de 1990 por medio de las alteraciones realizadas en el campo juridico y de sus desdoblamientos en las politicas y gestión para ese nivel de enseñanza en los sistemas públicos y privados que se configuran en efectivo proceso de reforma de ese nivel de enseñanza, aunque tenga prescindido de participación efectiva de los distintos segmentos de la sociedad académica, bajo los auspicios de la reforma del estado y de la centralidad conferida, en ese proceso, al sector privado. Asociado a los análisis realizados sobre el impacto de la reorganización de los sistemas público y privado de la educación superior, por medio de politicas de expansión, privatización y de alteración de la identidad de las IES, el presente artículo busca promover reflexiones e indicar principios esenciales a ser considerados en pro de la construción de un proceso de reestructuración de la educación superior que tenga por objetivo el rescate de la educación superior pública, democrática e de cualidad social entendida como un derecho social inalienable.

Palabras-clave: Educación superior. Políticas y gestión. Sistemas. Expansión. Privatización. Mercantilización.

Recebido: 18.04 .2005

Aceito: 22.06 .2005 
